\title{
Relationships of structure with function of the gonadotrophins
}

\author{
W. R. BUTT \\ From the Department of Clinical Endocrinology, Birmingham and Midland Hospital for Women, Showell \\ Green Lane, Sparkhill, Birmingham B11 4HL
}

The gonadotrophins are an interesting group of hormones in which to study relationships of structure with function. They are glycoproteins with carbohydrate components which confer important properties of biological activity and they consist of subunits which bear interesting relationships with one another. Furthermore, they are easier to study than some other hormones because of the specific biological assay methods available which are relatively simple to carry out.

\section{Function}

The action of a hormone generally consists of several parts. Firstly, there is the transfer of the hormone from the site of biosynthesis (or from injection site in experimental work) to the target site. The stability of the hormone in the circulation is important: the biological half life may need to be long or short according to the action of the particular hormone. Secondly, there is the recognition of the target and usually binding to it. Here subtle changes in structure may alter recognition and binding ability. Thirdly, there is action at the target site which may or may not be dependent on the intermediate action of a second messenger. In-vivo bioassays will usually give a measure of the total hormone activity but in-vitro assays will measure only one or two of the activities, such as binding or steroidogenesis. Another action, the immunological reactivity, may not correlate with the hormonal function. There are many instances where full immunological activity is retained in a chemically modified structure which possesses no hormonal activity.

There are well established in-vivo assays for the gonadotrophins. Follicle stimulating hormone (FSH) is usually measured by the ovarian augmentation method (Steelman and Pohley, 1953; Brown, 1955) and luteinizing hormone (LH) by the ovarian ascorbic acid depletion method of Parlow (1961) or the ventral prostate assay in hypophysectomised rats (Greep et al., 1941). There are many radioreceptor assays using ovarian or testicular prepara- tions in vitro for both FSH and LH (Catt et al. 1971; Lee and Ryan, 1971; Leidenberger ando Reichert, 1972; Gospodarowicz, 1973; Cheng, is 1975). A further function of the hormones in vitro may be observed by measuring steroids produced.by the gonads such as progesterone (Watson, $1971 ; \vec{\sim}$ Shirly and Stephenson, 1973) or testosterone을 (Dufau et al., 1972, 1976). The placental gonado-trophin (human chorionic gonadotrophin, HCG)@ is usually assayed by the techniques used for $\mathrm{LH}$.

Specific radioimmunoassays have now been described for each of the gonadotrophins and the immunological properties of the subunits have begn 9 studied extensively.

\section{Structure}

The pituitary gonadotrophins FSH and LH areo glycoproteins with a molecular weight of abouto 30000 . HCG has a molecular weight of over $\overrightarrow{0}$ 40000 . FSH and HCG contain up to $30 \%$ carbo- -3 hydrate. LH contains rather less. Sequential studies on the carbohydrates in FSH (Butt and Kennedy, 1972) and in HCG (Bahl, 1969) have shown thato sialic acid appears in terminal positions in both molecules and there are also terminal $\mathrm{N}$-acetyl-3. glucosamine and fucose residues. The sugar chainsi are attached to the peptide chains through asparagine and serine linkages.

One of the most interesting features is the sub-? unit structure. Each of the hormones consists of two non-covalently linked subunits $(\alpha$ and $\beta$ ). The $\alpha$. is similar in each but the $\beta$ is hormone-specific N Sequences have been determined for each of then subunits and some microheterogeneity has been recognized at the $\mathrm{N}$ - and $\mathrm{C}$-termini. There are up too 92 amino-acid residues in human $\alpha-\mathrm{FSH}, \alpha-\mathrm{LH}$, and $\alpha-H C G$ and the sequences are identical (Bellisario et al., 1973; Shome and Parlow, 1974a $\$$ Rathnam and Saxena, 1975). Carbohydrates are attached to asparagine residues at positions 42 and 78. $\beta$-FSH and $\beta$-LH each contain up to 118 residues, but the sequences vary considerably and the sugarsक्षे 
are attached at different positions (Carlsen et al., 1973; Shome and Parlow, 1974b; Saxena and Rathnam, 1976). $\beta$-HCG is interesting in that it contains some 30 extra amino-acids as an extension to the C-terminus. In view of the similar biological properties of $\mathrm{LH}$ and $\mathrm{HCG}$, not surprisingly the first 118 residues in $\beta$-HCG show considerable homology with the same residues in $\beta$ - $\mathrm{LH}$ and more than $80 \%$ are identical.

\section{Effect of chemical modifications on activity}

Even slight chemical modifications to the gonadotrophins may lead to loss of in-vivo biological activity (Butt, 1969, 1975). The FSH molecule is very sensitive to oxidation. Photo-oxidation, which affects histidine and tyrosine residues, or chloramine- $\mathrm{T}$, which oxidises cysteine and methionine, both destroy biological activity but radioimmunological activity is preserved. Not all the disulphide groups seem to be essential, however, since activity is retained after reduction with mercaptoethanol followed by alkylation with iodoacetamide (Rathnam and Saxena, 1972).

Modifications to the sugar residues have been studied extensively and particularly for FSH and HCG. The removal of terminal sialic acid residues from both hormones results in loss of in-vivo biological activity, while immunological activity remains (Ryle et al., 1970; Vaitukaitis and Ross, 1971). The loss of biological activity is related to the shortened half life of the molecule in the circulation. Intact FSH has a half life of about 90 minutes, but this is reduced to a few minutes after modification (Vaitukaitis and Ross, 1971) since the carbohydrate protects the hormone from binding to receptors in the liver (Morell et al., 1971). Nevertheless, the desialylated hormone retains certain biological characteristics. Like intact FSH, it stimulates the incorporation of thymidine into mouse ovaries in vitro (Ryle et al., 1970) and modified HCG binds to testicular receptors in the testis and stimulates steroidogenesis (Tsuruhara et al., 1972).

Moyle et al. (1975) made a careful study of the effects of the sequential removal of carbohydrates from HCG by means of specific carbohydrases. When sialic acid residues were removed binding activity to rat Leydig cells was not impaired and synthesis of testosterone and the accumulation of cyclic AMP was stimulated. Removal of the next carbohydrate, galactose, actually increased the binding capacity, as judged by the ability of the derivative to compete with HCG itself for binding sites. Although the ability to stimulate cyclic AMP accumulation was decreased the derivative was still capable of stimulating maximum steroidogenesis.
Further sequential removal of $\mathrm{N}$-acetylglucosamine and mannose residues caused some loss of binding ability, but even these derivatives retained steroidogenic capacity. Moyle et al. (1975) discussed the possible function of the carbohydrates on the basis of these and other observations, and suggested that they may stabilise the molecule against attack by peptidases in vivo, that they may facilitate binding to receptors, and that they enhance the production of the second messenger. It is difficult to explain, however, why complete stimulation of cyclic AMP requires the full carbohydrate complement since LH, which contains considerably less carbohydrate than HCG, stimulates cyclic AMP maximally (Moyle and Ramachandran, 1973).

\section{Subunit structure}

Purified subunits of the gonadotrophins are biologically inert. Early reports of activity probably arose because of inefficient separation of the two subunits. When pure $\alpha$ subunits are incubated under conditions in which reassociation of $\alpha$ and $\beta$ subunits occurs no biological activity is recovered (Reichert et al., 1973). Likewise $\beta$ subunits do not generate any activity on incubation. But when $\alpha$ is mixed with $\beta$ biologically active molecules are produced, the type of activity being that of the $\beta$ subunit.

Separate $\alpha$ and $\beta$ sub-units bind only weakly to target sites in vitro (Canfield et ál., 1971; Catt et al., 1973) and do not stimulate steroid synthesis (Braunstein et al., 1972; Channing and Kammerman, 1973; Morgan et al., 1974). This suggests that the binding sites of the intact molecules include part of both subunits or that they depend on the tertiary conformation. Combarnous and Hennen (1974) treated LH with carbodiimide to link the subunits covalently. When $0 \cdot 01 \mathrm{M}$ reagent was used there was no loss of activity. This suggests that after binding to the receptor no dissociation of the subunits is required to elicit biological activity.

Two of the seven tyrosine residues in intact $\mathrm{LH}$ are difficult to iodinate but when the subunits are separated they are readily iodinated. It may be that these two residues take part in the association of the subunits. Similarly, nitration of these groups with tetranitromethane occurs in only five of the seven residues in ovine LH but all seven are nitrated when the hormone is dissociated (Papkoff, 1973).

Cheng (1976a) studied the carboxymethylation of methionine in bovine $\mathrm{LH}$. There are four residues in the $\alpha$ and three in the $\beta$ subunits. Under the conditions of the experiments dissociation occurred but, since the modified subunits reassociated, methionine residues do not seem to be essential for 
interaction between subunits. When a total of three residues were alkylated biological activity in a radioreceptor assay was reduced to less than $5 \%$ of the original. Further alkylation reduced the activity still more. Immunological activity of reassociated material was not affected, however, so that the methionine residues are unlikely to be involved significantly in immunologically important sites. Nevertheless, it seems that at least one or two methionine residues in each chain are essential for in-vitro biological activity. Further studies on bovine LH (Cheng, 1976b) indicated that residues 8 and 33 in the $\alpha$ subunit and 52 in the $\beta$ subunit were preferentially modified by carboxymethylation. But when human $\alpha-\mathrm{LH}$, which contains valine not methionine at position 8 , was combined with carboxymethylated bovine $\beta$-LH a considerable amount of activity was regenerated. This suggests that the methionine at position 8 is not essential for biological activity but that the residues at $\alpha-33$ and $\beta-52$ are important for optimal binding by the $\mathrm{LH}$ to receptors.

\section{Conclusions}

The gonadotrophins are glycoproteins of about 30000 molecular weight and quite small changes to their structures may profoundly affect their hormonal activity. Certain components of the complete biological activities may be retained, however, particularly the capacity to bind to receptors and to promote steroidogenesis. Immunological activity may survive quite drastic modifications. There is no evidence that smaller fragments of these hormones retain in-vivo biological activity, so that the possibility of synthesising small compounds with gonadotrophic action seems remote.

\section{References}

Bahl, O. P. (1969). Human chorionic gonadotropin. II Nature of the carbohydrate units. Journal of Biological Chemistry, 244, 575.

Bellisario, R., Carlsen, R. B., and Bahl, O. P. (1973). Human chorionic gonadotropin. Linear amino acid sequence of the a subunit. Journal of Biological Chemistry, 248, 6796.

Braunstein, G. D., Vaitukaitis, J. L., and Ross, G. T. (1972). The in vivo behaviour of human chorionic gonadotropin after dissociation into subunits. Endocrinology, 91, 1030.

Brown, P. S. (1955). The assay of gonadotrophins from urine of non-pregnant human subjects. Journal of Endocrinology, 13, 59.

Butt, W. R. (1969). Chemistry of gonadotrophins in relation to their antigenic properties. Acta endocrinologica (Kbh), Suppl., 142, 13.

Butt, W. R. (1975). The gonadotrophins. In Hormone Chemistry, Vol. 1, 2nd edn., p. 140. Ellis Horwood, Chichester.

Butt, W. R., and Kennedy J. F. (1972). Relation of the structure of gonadotrophins to their biological and im- munological activities. In Structure-Activity Relationship. of Protein and Polypeptide Hormones, (Internationa Congress Series, 241), Pt. 1, edited by M. Margoulies anc? F. C. Greenwood, p. 115. Excerpta Medica Foundation: Amsterdam.

Canfield, R. E., Morgan, F. J., Kammerman, S., Bell, J. J and Agosto, G. M. (1971). Studies of human chorioni gonadotropin. Recent Progress in Hormone Rescarch $\frac{\bar{\sigma}}{\bar{D}}$ 27, 121 .

Carlsen, R. B., Bahl, O. P., and Swaminathan, N. (1973) Human chorionic gonadotropin. Linear amino acio sequence of the $\beta$ subunit. Journal of Biological Chemistry 248, 6810 .

Catt, K. J., Dufau, M. L., and Tsuruhara, T. (1971). Studies on a radioligand-receptor assay system for luteinizing hormone and chorionic gonadotropin. Journal of Clinica Endocrinology and Metabolism, 32, 860.

Catt, K. J., Dufau, M. L., and Tsuruhara, T. (1973). Absence응 of intrinsic biological activity in LH and hCG subunitsos Journal of Clinical Endocrinology and Metabolism, 36, 73.

Channing, C. P., and Kammerman, S. (1973). Effects of hCG, asialo-hCG and the subunits of hCG upon luteiniza: tion of monkey granulosa cell cultures. Endocrinology, 93 1035.

Cheng, K. W. (1975). A radioreceptor assay for follicle $=$ stimulating hormone. Journal of Clinical Endocrinologic and Metabolism, 41, 581 .

Cheng, K. W. (1976a). Carboxymethylation of methionine residues in bovine pituitary luteinizing hormone and its subunits. Effects on the binding activity with receptor sites and interactions between subunits. Biochemicate Journal, 159, 71 .

Cheng, K. W. (1976b). Carboxymethylation of methion residues in bovine pituitary luteinizing hormone and Its subunits. Location of specifically modified methioring residues. Biochemical Journal, 159, 79.

Combarnous, Y., and Hennen, G. (1974). Luteinizing hor mone derivatives with covalently-linked subunits. FEB Letters, 44, 224

Dufau, M. L., Catt, K. J., and Tsuruhara, T. (1972). sensitive gonadotropin responsive system: radioimmuno윽 assay of testosterone production by the rat testis in vitro Endocrinology, 90, 1032.

Dufau, M. L., Pock, R., Neubauer, A., and Catt, K. J. (1976) In vitro bioassay of $\mathrm{LH}$ in human serum: the rat interstitian cell testosterone (RICT) assay. Journal of Clinical Endo? crinology and Metabolism, 42, 958.

Gospodarowicz, D. (1973). Properties of the luteinizing hormone receptor of isolated bovine corpus luteum plasma membranes. Journal of Biological Chemistry, 248, 5042.

Greep, R. O., Van Dyke, H. B., and Chow, B. F. (1941)? Use of anterior lobe of prostate gland in the assay of metakentrin. Proceedings of the Society for Experimentah Biology and Medicine, 46, 644

Lee, C. Y., and Ryan, R. J. (1971). The uptake of humanluteinizing hormone (hLH) by slices of luteinized ran ovaries. Endocrinology, 89, 1515.

Leidenberger, F., and Reichert, L. E., Jr (1972). Evaluation of a rat testis homogenate radioligand receptor assay fon human pituitary LH. Endocrinology, 91, 901.

Morell, A. G., Gregoriadis, G., Scheinberg, I. H., Hickman, J and Ashwell, G. (1971). The role of sialic acid in determin ing the survival of glycoproteins in the circulation. Journa of Biological Chemistry, 246, 1461.

Morgan, F. J., Canfield, R. E., Vaitukaitis, J. L., and Ross; G. T. (1974). Properties of the subunits of human chorionic gonadotropin. Endocrinology, 94, 1601.

Moyle, W. R., Bahl, O. P., and März, L. (1975). Role of thछ carbohydrates in human chorionic gonadotropin in th\&D mechanism of hormone action. Journal of Biologica尺 
Chemistry, 250, 9163.

Moyle, W. R., and Ramachandran, J. (1973). Effect of LH on steroidogenesis and cyclic AMP accumulation in rat Leydig cell preparations and mouse tumor Leydig cells. Endocrinology, 93, 127.

Papkoff, H. (1973). The chemistry of the interstitial cellstimulating hormone of ovine pituitary origin. In Hormonal Proteins and Peptides, Vol. 1, edited by C. H. Li, p. 59. Academic Press, New York and London.

Parlow, A. F. (1961). In Human Pituitary Gonadotropins, edited by A. Albert, p. 300. Thomas, Springfield, Illinois.

Rathnam, P., and Saxena, B. B. (1972). In Gonadotropins, edited by B. B. Saxena, C. G. Beling, and H. M. Gandy, p. 120. Wiley-Interscience, New York.

Rathnam, P., and Saxena, B. B. (1975). Primary amino acid sequence of FSH from pituitary glands, I: $a$-subunit. Journal of Biological Chemistry, 250, 6735.

Reichert, L. E., Jr, Leidenberger, F., and Trowbridge, C. G. (1973). Studies on luteinizing hormone and its subunits: development and application of a radioligand-receptor assay and properties of the hormone-receptor interaction. Recent Progress in Hormone Research, 29, 497.

Ryle, M., Chaplin, M. F., Gray, C. J., and Kennedy, J. F. (1970). The action of a neuraminic acid-free derivative of FSH on mouse ovaries cultured in vitro. In Gonadotrophins and Ovarian Development, edited by W. R. Butt, A. C. Crooke and M. Ryle, p. 98. Livingstone, Edinburgh and London.

Saxena, B. B., and Rathnam, P. (1976). Amino acid sequence of the $\beta$ subunit of follicle-stimulating hormone from human pituitary glands. Journal of Biological Chemistry, 251, 993.

Shirley, A., and Stephenson, J. (1973). Progestin production in vitro by rabbit granulosa cells as an assay for luteinizing hormone. Journal of Endocrinology, 58, 345.

Shome, B., and Parlow, A. F. (1974a). Human follicle stimulating hormone (hFSH): first proposal for the amino acid sequence of the $a$-subunit (hFSHa) and first demonstration of its identity with the $a$-subunit of human luteinizing hormone (hLHa). Journal of Clinical Endocrinology and Metabolism, 39, 199.

Shome, B., and Parlow, A. F. (1974b). Human follicle stimulating hormone: first proposal for the amino acid sequence of the hormone-specific, $\beta$-subunit (hFSH $\beta)$. Journal of Clinical Endocrinology and Metabolism, 39, 203.

Steelman, S. L., and Pohley, F. M. (1953). Assay of the follicle stimulating hormone based on the augmentation with human chorionic gonadotropin. Endocrinology, 53, 604.

Tsuruhara, T., Dufau, M. L., Hickman, J., and Catt, K. J. (1972). Biological properties of hCG after removal of terminal sialic acid and galactose residues. Endocrinology, 91, 296.

Vaitukaitis, J. L., and Ross, G. T. (1971). Altered biologic and immunologic activities of progressively desialylated human urinary FSH. Journal of Clinical Endocrinology and Metabolism, 33, 308.

Watson, J. (1971). The bioassay of luteinizing hormone by progesterone synthesis in ovarian tissue of prolactintreated rats in vitro. Journal of Endocrinology, 50, 711. 